\title{
Thermomagnetic Study for Identification of Mineral Phases
}

\author{
Anderson Alves Cunha ${ }^{a, c}$, Fabiane Leocádia da Silva ${ }^{*}$, Blênio Márcio Cunha Silva ${ }^{c}$, Jefferson \\ Januário Mendes ${ }^{a, b, c}$, Ruben Antonio Llobell Solé ${ }^{c}$, Fernando Gabriel da Silva Araújo ${ }^{a, c}$ \\ ${ }^{a}$ REDEMAT - Universidade Federal de Ouro Preto, $M G$, Brasil \\ ${ }^{b}$ Instituto Federal de Minas Gerais - IFMG, MG, Brasil \\ ${ }^{c}$ Departamento de Pesquisa em Engenharia e Educação Continuada - Fundação Gorceix
}

Received: January 16, 2017; Revised: April 11, 2017; Accepted: May 01, 2017

\begin{abstract}
The characterization of materials is an area of extreme importance for engineering, it uses a range of instrumental techniques to provide an information bank for material analysis and selection. In the treatment of iron ore the mineralogical characterization is done, almost exclusively, by optical microscopy. However, materials with very fine granulometry, below $4 \mu \mathrm{m}$, make their preparation and visualization restricted in this equipment. The present work aims to identify the minerals Hematite, Magnetite and Goethite in samples of tailings from the iron ore processing, employing a Bartington MS3 that evaluates the magnetic susceptibility as a function of the temperature. These measurements make it possible to identify Curie temperatures characteristic of Magnetite $\left(580^{\circ} \mathrm{C}\right)$ and Hematite $(675$ $\left.{ }^{\circ} \mathrm{C}\right)$, as well as Goethite's Neel temperature $\left(120^{\circ} \mathrm{C}\right)$. The results showed that the application of the technique is of great value for the identification of the magnetic bearing minerals and the quantification of the magnetic potential of the sample.
\end{abstract}

Keywords: Curie temperature, Néel temperature, thermomagnetic study, magnetic susceptibility.

\section{Introduction}

The materials can be classified according to an orientation of their magnetic moments in relation to the external magnetic field. These classes are: diamagnetic, paramagnetic, ferromagnetic, antiferromagnetic and ferrimagnetic. The diamagnetic materials present negative magnetic susceptibility, whereas in the paramagnetic materials the susceptibility is positive. Diamagnetism is present to a greater or lesser extent in all materials, however, in most of them its intensity is very low and only persists as long as an external magnetic field is applied. In the absence of external field, the atoms of a diamagnetic material have zero momentum. The phenomenon of diamagnetism is often masked by stronger ones, such as paramagnetism and ferromagnetism ${ }^{1}$. According to Dunlop and Ozdemir (1997), most non-ferrous minerals such as quartz, calcite and feldspar are purely diamagnetic, with small magnetic susceptibility and independent of temperature. Thus, if a sample contains a small amount of ferromagnetic and paramagnetic minerals, at high temperatures, the magnetic moment of a quartz sample can be verified ${ }^{2}$. The magnetic susceptibility of diamagnetic materials is practically non-temperature dependent, due to the fact that the diamagnetism does not arise from the interaction between the magnetic field and the moment that can be disordered with the temperature, but of the interaction of the field with the electronic charges altering its speed. Since the speed of electrons is a function of electronic states,

*e-mail: fabileocadia@yahoo.com.b and these are independent of temperature, this also makes the susceptibility not dependent on temperature ${ }^{3}$.

In paramagnetic materials, individual atoms have magnetic moments, but their random orientation results in null magnetization for a group of atoms, thus being nonmagnetic in the absence of an external field and magnetic on the influence of an applied magnetic field. The response to the external magnetic field in paramagnetic materials is much less intense than in ferromagnetic ones.

Ferromagnetic materials are magnetic in the absence of an applied external magnetic field. When a magnetic field is absent, the material has spontaneous magnetization, which is a result of ordered magnetic moments, in orther words, for ferromagnetism, the atoms are symmetrical and aligned in the same direction, creating a permanent magnetic field. When an external magnetic field is applied to a ferromagnetic material all its magnetic moments remain ordered, but now in the same direction and direction of the applied field. However, if the magnetic field decreases, the magnetic flux will not reduce rapidly as the field, since the ferromagnetic materials has as characteristic the tendency of conservation of its magnetic properties even in the absence of the stimulus that generated them. The materials are only ferromagnetic below their corresponding Curie temperature - temperature at which the material becomes paramagnetic, because the atoms lose their ordered magnetic moments ${ }^{1}$. Analogously to the Curie temperature, the temperature of Neel is defined for the case of antiferromagnetic substances. When the magnetic moments cancel out altogether, the structure is classified as 
antiferromagnetic. In a different way, when the moments in one direction exceed those of the opposite direction, the structure is classified as ferrimagnetic ${ }^{2}$.

For ferrimagnetic materials, when it does not have an external magnetic field applied, the material has a spontaneous magnetism which is the result of ordered magnetic moments. In this case, there are magnetic moments of an ion that are aligned in one direction with a certain magnitude, and others that are aligned in the opposite direction, with a smaller magnitude, because of this there is a resulting magnetic field present. For antiferromagnetic materials, the magnetic moments are the same and are aligned in opposite directions, resulting in a spontaneous magnetic moment null at all temperatures below the Neel temperature. These materials are also poorly magnetic in the presence of an applied magnetic field. Figure 1 shows the structure and magnetic classification of the main iron ore in Brazil.

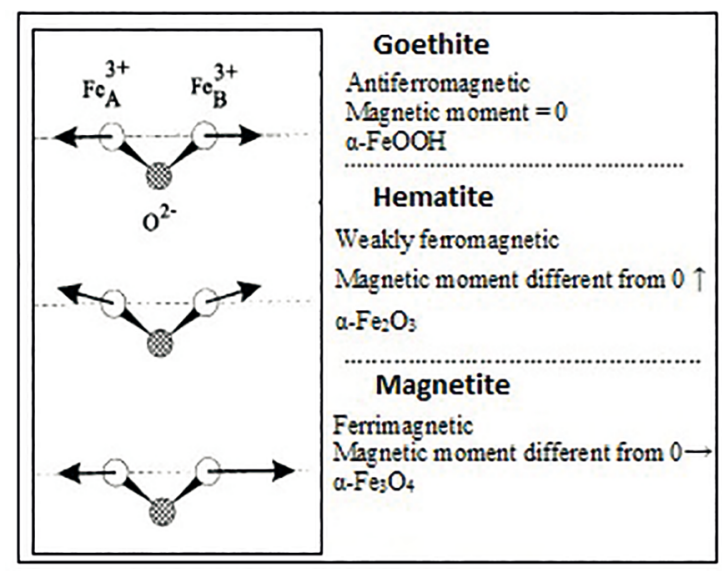

Figure 1. Magnetic structure of the main iron ore in Brazil ${ }^{4}$.

The magnetic susceptibilimeter is a technique used to determine phase transformations, Curie and/or Neel temperatures and to identify magnetic bearing minerals from a sample. The equipment operates by generating a low-frequency, lowintensity alternating current magnetic field around a sensor. When the sample is inserted into the carrier, the resulting field change is identified by the system and converted into magnetic susceptibility. It is an indestructible technique the samples do not need a special preparation. In order to target certain material for a given technology, it is essential to know its specific characteristics and properties. Hematite, Goethite and Magnetite are the main ores containing iron and the iron ore minerals present in iron ore are: Quartz, Kaolinite and Gibbite.

The present work aims to identify the minerals Hematite, Magnetite and Goethite in samples of tailings from the iron ore processing, using a magnetic susceptibility that evaluates the magnetic susceptibility as a function of temperature. These measurements make it possible to identify the Curie temperatures characteristic of Magnetite $\left(580^{\circ} \mathrm{C}\right)$ and Hematite $\left(675^{\circ} \mathrm{C}\right)$, as well as Goethita's Néel temperature $\left(120^{\circ} \mathrm{C}\right)$.

\section{Materials and Methods}

The methodology consisted, firstly, of characterizing four types of tailings from iron ore processing by means of X-ray diffraction and X-ray fluorescence and then performing tests on the magnetic susceptibilime with ambient atmosphere (Air), varying the temperature between 30 and $710^{\circ} \mathrm{C}$ with rate of heating and cooling of $15^{\circ} \mathrm{C} / \mathrm{min}$. Figure 2 shows the flowchart of the tests performed for each sample $\mathrm{e}^{5,6}$.

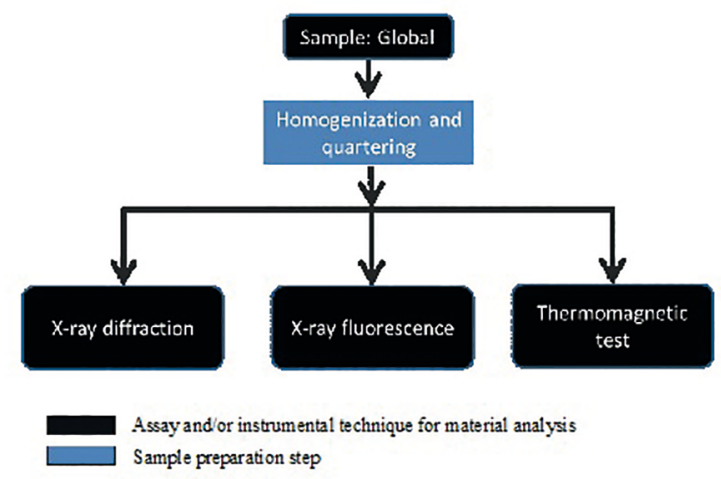

Figure 2. Flowchart of the tests and the preparation stage carried out for each sample.

\section{Results and Discussion}

\subsection{X-ray fluorescence}

The average chemical analysis for the compositions are shown in Table 1. Note, higher silica contents in the flotation tailings, for a while, In the mud there are higher iron contents, the other oxides, Even with low levels will be relevant for the determination of the present phases. It is also verified, higher loss on ignition (LOI) in ultrafine tailings samples, mainly due to the content of hydrated minerals, such as Goethite.

\subsection{XRD analysis}

Figures 3 and 4 show the X-ray diffractograms for flotation tailings 01,02 and ultrafine 01,02 respectively.

Note that the peak of the mineral quartz is the most evident in the flotation tailings and in the ultrafine the hematite is in higher concentration. The X-ray diffractograms confirm the chemical analyzes obtained for the tailings.

\subsection{Thermomagnetic study}

The thermomagnetic study involves thermal processing in the air and without addition of other chemical components, which determined Curie temperatures of magnetite (580 ${ }^{\circ} \mathrm{C}$ ) and hematite $\left(675^{\circ} \mathrm{C}\right)$, evidenced by the increase of susceptibility near temperatures Magnetization critics, called the Hopkinson effect ${ }^{7}$. The heating and cooling curves are 
Table 1. Mean chemical analysis of tailings by X-ray fluorescence.

\begin{tabular}{lcccccccccccccc}
\hline \multirow{2}{*}{ Tailings } & $\mathrm{FeO}$ & $\mathrm{Fe}$ & $\mathrm{SiO}_{2}$ & $\mathrm{Al}_{2} \mathrm{O}_{3}$ & $\mathrm{CaO}$ & $\mathrm{MgO}$ & $\mathrm{TiO}_{2}$ & $\mathrm{Na}_{2} \mathrm{O}$ & $\mathrm{K}_{2} \mathrm{O}$ & $\mathrm{P}$ & $\mathrm{Mn}$ & $\mathrm{Fe}_{2} \mathrm{O}_{3-} \mathrm{O}$ & $\mathrm{LOI}$ \\
$\%$ & $\%$ & $\%$ & $\%$ & $\%$ & $\%$ & $\%$ & $\%$ & $\%$ & $\%$ & $\%$ & $\%$ & $\%$ \\
\hline Flotation 1 & $<0.14$ & 23.3 & 65 & 0.5 & 0.07 & $<0.1$ & 0.1 & $<0.1$ & 0.01 & 0.02 & 0.1 & 34.7 & 0.7 \\
Flotation 2 & 0.43 & 12.8 & 80 & 0.6 & $<0.01$ & $<0.1$ & 0 & $<0.1$ & $<0.01$ & 0.01 & 0 & 18.9 & 0.8 \\
Ultrafine 1 & $<0.14$ & 43.8 & 21 & 6 & 0.45 & 1.2 & 0.2 & $<0.1$ & 0.06 & 0.14 & 1.7 & 65 & 4.7 \\
Ultrafine 2 & $<0.14$ & 51 & 13 & 6 & 0.01 & $<0.1$ & 0.2 & $<0.1$ & 0.02 & 0.13 & 0.1 & 74.4 & 7.4 \\
\hline
\end{tabular}
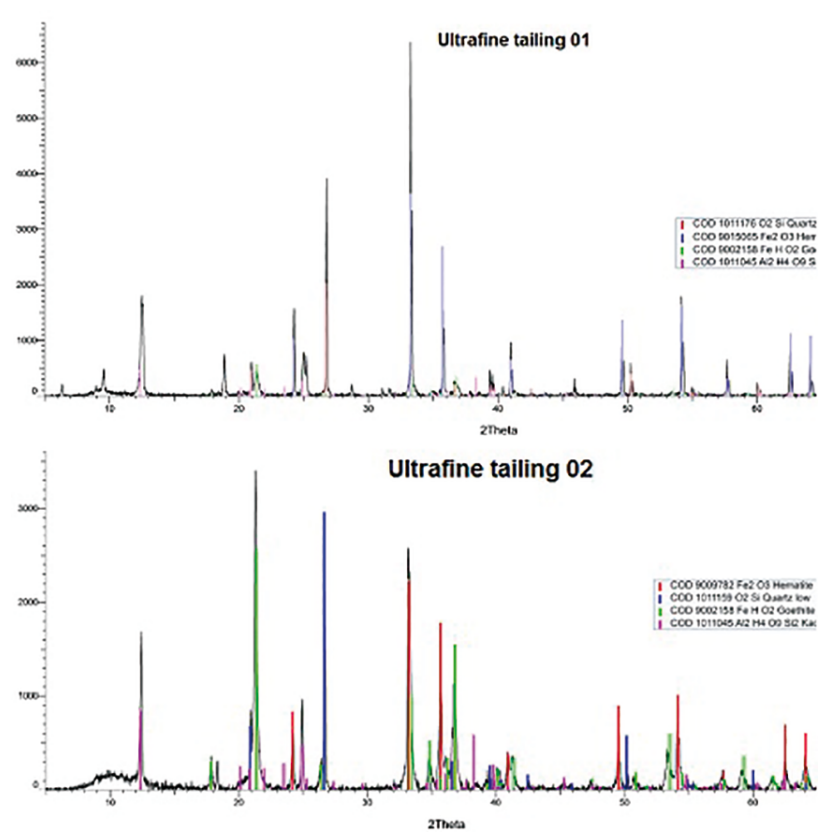

Figure 3. X-ray diffraction for the tailings (ultrafine 01 and 02).
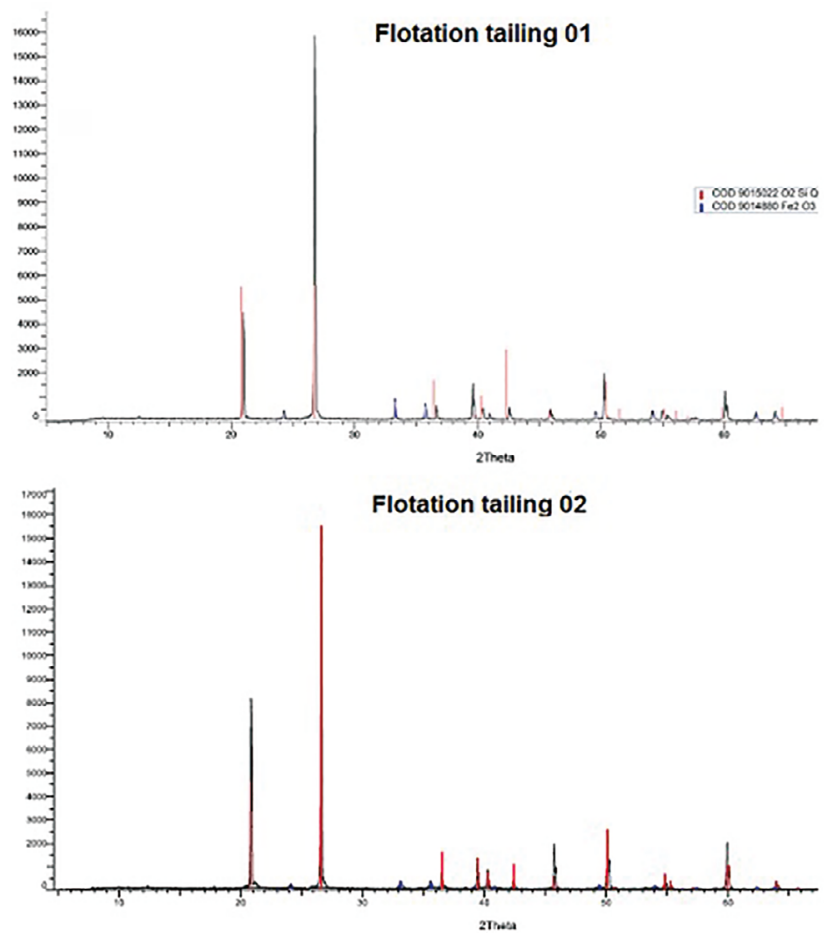

Figure 4. X-ray diffraction for flotation tailings 01 and 02. 

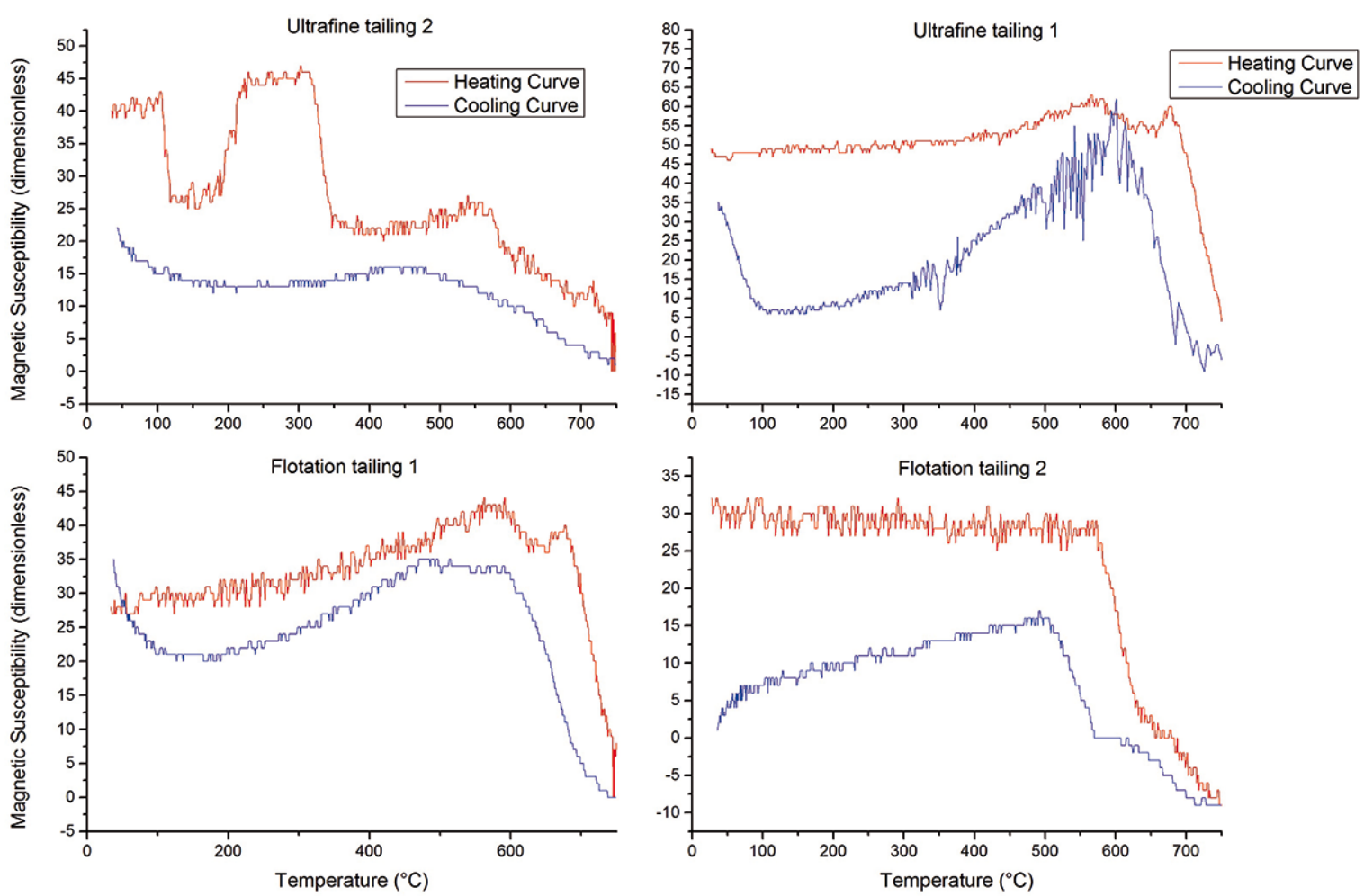

Figure 5. Thermomagnetic curves of the tailings.

said to be reversible if mineralogical transformations do not occur during heating and are irreversible otherwise. Thus, from the comparison of the shape of the heating curve and the cooling curve, we can infer the possible structural chemical transformations. Figure 5 shows the thermomagnetic air tests of the tailings samples.

In the sample of ultrafine tailing 2 it is observed the characteristic of irreversibility of the curves, demonstrating that there was mineralogical transformation, which was also noticed in the sample of ultrafine tailing 1. As the ultrafine tailings sample contains high loss by calcination, at high temperatures the hydrated minerals undergo a dehydration process, modifying its structure and influenced the irreversible shape of the curves.

In the sample of flotation tailing 1, it was identified the presence of magnetite $\left(580{ }^{\circ} \mathrm{C}\right)$ and hematite $\left(675^{\circ} \mathrm{C}\right)$ by characteristic Hopkinson peaks, and at high temperatures the sample exhibited a characteristic diamagnetic behavior of quartz. In the flotation tailing 2 the presence of magnetite and hematite was also identified, as well as negative values of susceptibility to high temperatures due to the presence of quartz. In the flotation tailing 1 , a great geometric similarity of the heating and cooling curves is observed, evidencing a reversible curve ${ }^{7,8}$.

\section{Conclusions}

The thermomagnetic study revealed that the tailings present magnetic susceptibility curves characteristic of materials containing iron oxides. Flotation tailings presented negative magnetic susceptibility indices evidencing the diamagnetic behavior due to the predominance of quartz. Materials subjected to high temperatures tend to present irreversible thermomagnetic curves, especially the samples with hydrated minerals, which show mineralogical transformations. Ultrafine tailings presented a higher magnetic potential than flotation tailings because of the amount of hematite and magnetite present in the sample. The investigation of magnetic susceptibility is an important technique for the technological characterization of materials.

\section{Acknowledgments}

This work was supported by the Universidade Federal de Ouro Preto (UFOP)/ REDEMAT, CAPES and Fundação Gorceix.

\section{References}

1. Callister WD. Ciência e Engenharia dos Materiais - Uma Introdução. 8 $8^{\text {a }}$ ed. São Paulo: LTC; 2012.

2. Dunlop DJ, Özdemir Ö. Rock Magnetism Fundamentals and Frontiers. New York: Cambridge University Press; 1997.

3. Arantes FR. Estudo do comportamento magnético de nanopartículas de magnetita e nanofios de níquel diluídos em cristais líquidos liotrópicos. [Dissertation]. São Paulo: Instituto de Física, Universidade de São Paulo; 2010. 117 f. 
4. Wolff AP, Costa GM, Dutra FC. A Comparative Study of UltraFine Iron Ore Tailings from Brazil. Mineral Processing \& Extractive Metallurgy Review. 2011;32(1):47-59.

5. Da Silva FL, Araújo FGS, Teixeira MP, Gomes RC, von Krüger FL. Study of the recovery and recycling of tailings from the concentration of iron ore for the production of ceramic. Ceramics International. 2014;40(10 Pt B):16085-16089.

6. Silva FL, Araújo FGS, Castro CG, Mendes JJ, von Krüger FL. Recycling of Concentration Tailings of Iron Ore for the Production of Concrete Block (Pavers). Materials Science Forum. 2014;775-776:631-634.
7. Hunt CP, Moskowitz BM, Banerjee SK. Magnetic properties of rocks and minerals. In: Ahrens TJ, ed. Rock Physics and Phase Relations: A Handbook of Physical Constants, volume 3. Washington: American Geophysical Union; 1995. p. 189-204.

8. Srivastava MP, Pan SK, Prasad N, Mishra BK. Characterization and processing of iron ore fines of Kiriburu deposit of India. International Journal of Mineral Processing. 2001;61(2):93-107. 